\title{
Numerical method to measure velocity integration, stroke volume and cardiac output while rest: using 2D fluid-solid interaction model
}

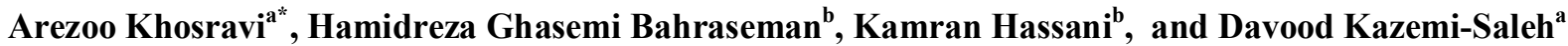

${ }^{a}$ Atherosclerosis research center, Baqiyatallah University of Medical Sciences, Tehran, Iran

${ }^{b}$ Department of Biomechanics, Science and Research Branch, Islamic Azad University, Tehran, Iran

\begin{tabular}{lll}
\hline A R T ICLE I NFO ABSTRACT & A A
\end{tabular}

Article history:

Received September 20, 2013

Received in Revised form

October, 14, 2013

Accepted 9 February 2014

Available online

12 February 2014

Keywords:

Echo-Doppler flow

Fluid-structure interaction

Hemodynamics

Natural aortic valve

\begin{abstract}
Development of knowledge of cardiovascular diseases and treatments strongly depends on understanding of hemodynamic measurements. Hemodynamic parameters, therefore, have been investigated using simulation-based methods. A two-dimensional model was applied for seven healthy subjects with echo-Doppler at rest. Echocardiography imaging was also utilized to gain the geometry of the aortic valve. Fluid-Structure Interaction (FSI) model was carried out, coupling an Arbitrary Lagrangian-Eulerian mesh. Pressure loads were used as boundary conditions on the valve's ventricular and aortic sides. Pressure loads used were the calculated brachial pressures plus differences between brachial, central and left ventricular pressures. The FSI model predicted the velocity integration, stroke volume and cardiac output over a range of heart rates while rest. Numerical results generally had a difference of 5.4 to $15.87 \%$ with Doppler results. Linear correlations between numerical and clinical approaches have been applied. This makes possible predictions achieved from the FSI model to be gained which are highly accurate (e.g. correlation factor $r=0.995,0.990$ and 0.990 for velocity integration, stroke volume and cardiac output, respectively). The obtained numerical results showed that numerical methods can be combined with clinical measurements to provide good estimates of patient specific hemodynamics for different subjects.
\end{abstract}

(C) 2014 Growing Science Ltd. All rights reserved.

\section{Introduction}

Disease of the heart and blood vessels is a major factor of mortality (Murphy \& Xu, 2012). To magnify the impact of recent methods applied to study the cardiovascular performance, it is crucial that they are applied in clinically relevant researches. Comprehending changes to blood flow is a fundamental element in cardiovascular diagnosis (Bodnar et al., 1999; Butchart et al., 2003; Criner et al., 2010; Giddens et al., 1993). For example, such understanding may be used to evaluate patients with coronary artery disease (Piérard \& Lancellotti, 2007). Present invasive/non-invasive methods,

* Corresponding author.

E-mail addresses: arekhosravi@yahoo.com (A. Khosravi) 
moreover, used to evaluate cardiovascular function have several restrictions, such as being arduous and precious to use, as well as not being hazard free (Laske et al., 1996). Instead, mathematical methods could be used to determine hemodynamics in addition to reducing the need for invasive procedures.

Numerical methods have the possibility to estimate hemodynamics, only if the accurate boundary conditions are used. Fluid-Structure Interaction (FSI) technique is pretty well suited to heart valve simulations, like the aortic valve. Fluid flow around a valve causes its deflexion and deformation and regulates valve opening and prepare it for closure (Pedley et al., 1978). Such recirculation depends on the valve cusps deformation (Bellhouse, 1972). FSI simulations integrate Finite Element Analysis of a solid with Computational Fluid Dynamics to evaluate flow. FSI uses of an Arbitrary-LagrangeEuler mesh to analyze the coupled physics (Donea et al., 1982; Formaggia \& Nobile, 1999). A concurrent FSI simulation could be applicable by constraints at boundaries which are shared by both the structure and fluid. The reaction force of fluid exerts on the structure at the shared boundary, while fluid velocity is restricted to be equal to the structural temporal deformation (Dowell \& Hall, 2001; Van de Vosse et al., 2003).

FSI method has been used to examine biological (Al-Atabi et al., 2010; Espino et al., 2012a,b,c) and artificial (Piérard \& Lancellotti, 2007, Winslow, 1966) heart valves. The aortic valve, for example, has been modelled in two- dimensions (De Hart et al., 2000) and three-dimensions (De Hart et al., 2003a) as well as its leaflets have been considered as fiber-reinforced composites (De Hart et al., 2003b). Griffith and Peskin (2005) and Griffith et al. (2007, 2009) provided a research included an immersed boundary procedure for computational analysis of fluid-structure interaction of flexible aortic valve for rest stage. Several aortic valve FSI simulations validated experimentally (De Hart et al., 2000, 2003; Labrosse et al., 2010; Nobili et al., 2008). Such researches confirm the possibility of developing complex aortic valve dynamics. However, up to now they have not been integrated with non-invasive clinical computations to estimate a patient's cardiac hemodynamics. Alterations to such evaluation have not numerically been analysed either for several subjects.

The aim of this study is to evaluate hemodynamics through aortic valve while rest. The twodimensional aortic valve FSI model has been used to determine changes to blood flow. The boundary conditions as well as valve dimensions were obtained from seven subjects. Blood flow parameters assessed include: velocity integration, cardiac output and stroke volume.

\section{Methods}

\subsection{Combined clinical and numerical approach}

Workflow of the study was briefly provided in Fig. 1. Seven healthy subjects, aged 33 to 56 years old, participated in this study with their hemodynamic data recorded during rest. Informed consent was gained for the participants according to protocols confirmed by the Department of Cardiovascular Imaging (Atherosclerosis research centre, Tehran, Iran). Following clinical examination, the subjects were found to perform normal cardiovascular functions. Systolic and diastolic pressures of the brachial artery were obtained (Table 1). Eq. (1) and Eq. (2) were applied to measure the central pressure respecting to brachial pressure measurements (Park et al., 2011).

Central systolic pressure $\approx$ Brachial systolic pressure +2.25 ,

Central diastolic pressure $\approx$ Brachial diastolic pressure -5.45 ,

where all pressures were measured in $\mathrm{mmHg}$. 


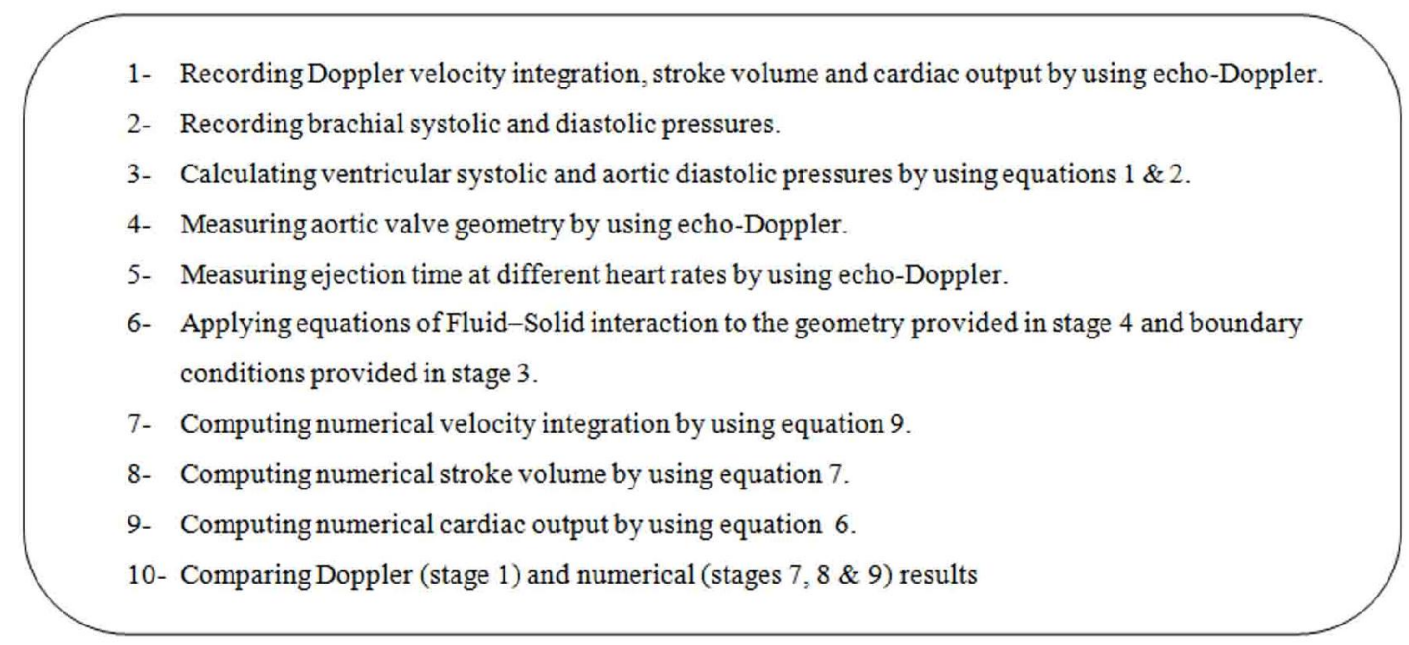

Fig. 1. workflow of study

As well as this, left ventricular systolic pressure was gained from the calculated central systolic pressure. A pressure difference of around $5 \mathrm{mmHg}$ was previously reported between peak left ventricular systolic pressure and central systolic pressure, using catheterization (Laske et al., 1996). The ejection times were also obtained from Doppler-flow imaging under B-mode.

Table 1

Systolic, diastolic pressures and ejection time for each subject

\begin{tabular}{ccc|cccc}
\hline Subject & HR & ET & LBSP & LBDP & VSP & CDP \\
\hline 1 & 80 & 243 & 124 & 86 & 132 & 70 \\
\hline 2 & 74 & 303 & 118 & 80 & 126 & 64 \\
3 & 70 & 288 & 115 & 76 & 123 & 60 \\
4 & 77 & 273 & 133 & 83 & 141 & 67 \\
5 & 52 & 240 & 113 & 58 & 121 & 42 \\
6 & 59 & 303 & 98 & 65 & 106 & 49 \\
7 & 74 & 245 & 110 & 80 & 118 & 64 \\
\hline
\end{tabular}

HR: Heart rate;

ET: Ejection time;

LBSP: Left brachial systolic pressure;

LBDP: Left brachial diastolic pressure;

VSP: Ventricular systolic pressure;

CDP: Central diastolic pressure;

\section{Table 2}

Geometric data of the aortic valves

\begin{tabular}{|c|c|c|c|c|c|c|}
\hline 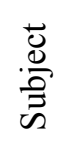 & $\begin{array}{c}\text { Maximum } \\
\text { diameter of } \\
\text { normal aortic root } \\
(\mathrm{mm})\end{array}$ & $\begin{array}{l}\text { Ventricular } \\
\text { side diameter } \\
(\mathrm{mm})\end{array}$ & $\begin{array}{l}\text { Aortic side } \\
\text { diameter } \\
(\mathrm{mm})\end{array}$ & $\begin{array}{l}\text { Ascending aorta diameter } \\
\text { after sinotubular junction } \\
(\mathrm{mm})\end{array}$ & $\begin{array}{l}\text { Leaflet's } \\
\text { length } \\
\text { (mm) }\end{array}$ & $\begin{array}{l}\text { Valve's } \\
\text { height } \\
(\mathrm{mm})\end{array}$ \\
\hline 1 & 29.7 & 20.5 & 25.1 & 31.6 & 12.6 & 21 \\
\hline 2 & 33.8 & 23.1 & 30.3 & 35.4 & 14.9 & 27.4 \\
\hline 3 & 33.9 & 21 & 30 & 35.9 & 14.5 & 30.9 \\
\hline 4 & 28 & 20 & 26.6 & 31.7 & 10.8 & 20.6 \\
\hline 5 & 29.4 & 19.4 & 26.5 & 31.3 & 10.6 & 19.1 \\
\hline 6 & 26.5 & 20 & 26.6 & 31.7 & 10.4 & 19.8 \\
\hline 7 & 29 & 19.2 & 25.2 & 28.5 & 11.5 & 19.3 \\
\hline
\end{tabular}


The aortic valve geometries modelled are presented in Fig. 2 and dimensions are provided in Table 2. Dimensions were gained regarding T-wave and T-wave time of ECG. The two cusps were taken into account to be homogenous, isotropic and to have a linear stress-strain relationship. This assumption has been used in other heart valve models (De Hart et al., 2000; Espino et al., 2012 a,b; Weinberg \& Kaazempur-Mofrad, 2008). Blood was also supposed to be Newtonian and an incompressible fluid (Pedley et al., 1978). All material properties are provided in Table 3 and were obtained from the literature (Govindarajan et al., 2010; Koch et al., 2010).

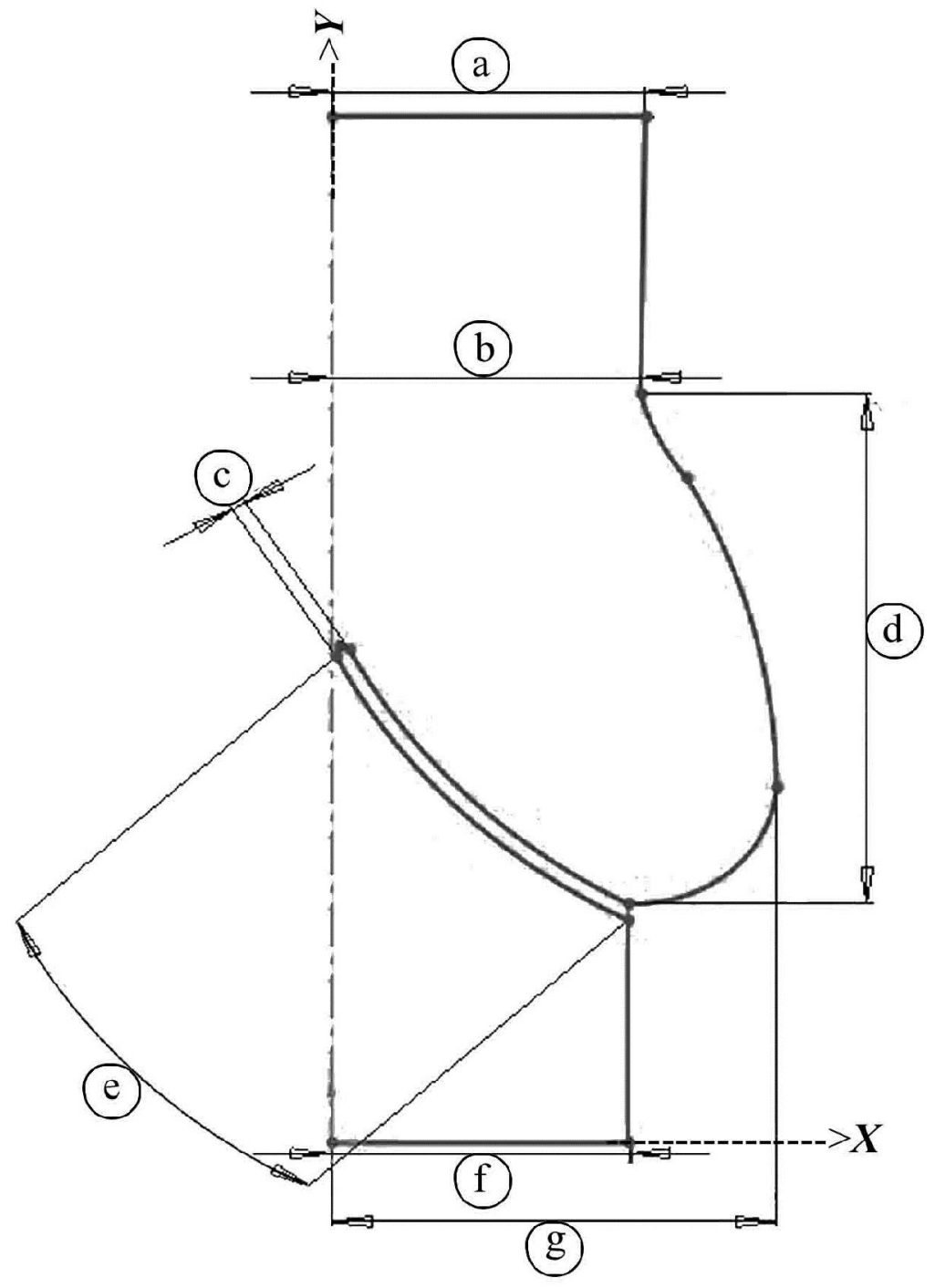

Fig. 2. Aortic valve model

\section{Table 3}

Mechanical properties

\begin{tabular}{|c|c|c|c|c|c|}
\hline Viscosity (Pa.s) & Density & $(\mathrm{kg} / \mathrm{m} 3)$ & Young's modulus & $(\mathrm{N} / \mathrm{m} 2)$ & Poisson ratio \\
\hline $3.5 \times 10^{-3}$ & & & $6.885 \times 10^{6}$ & & 0.4999 \\
\hline
\end{tabular}

For fluid boundaries (Fig. 2), pressure was used at the inflow boundary of the aortic root at the left ventricular side. A moving ALE mesh was applied which enabled the deformation of the fluid mesh to be tracked without the need for re-meshing (Weinberg \& Kaazempur-Mofrad, 2008). Second order 
Lagrangian elements were used to define the mesh (Fig. 3). The finite element analysis package Comsol Multi-physics (v4.2, Comsol Ltd, Cambridgeshire, UK) was used to solve the FSI model under time dependent conditions (Espino et al., 2012a; Formaggia \& Nobile, 1999).

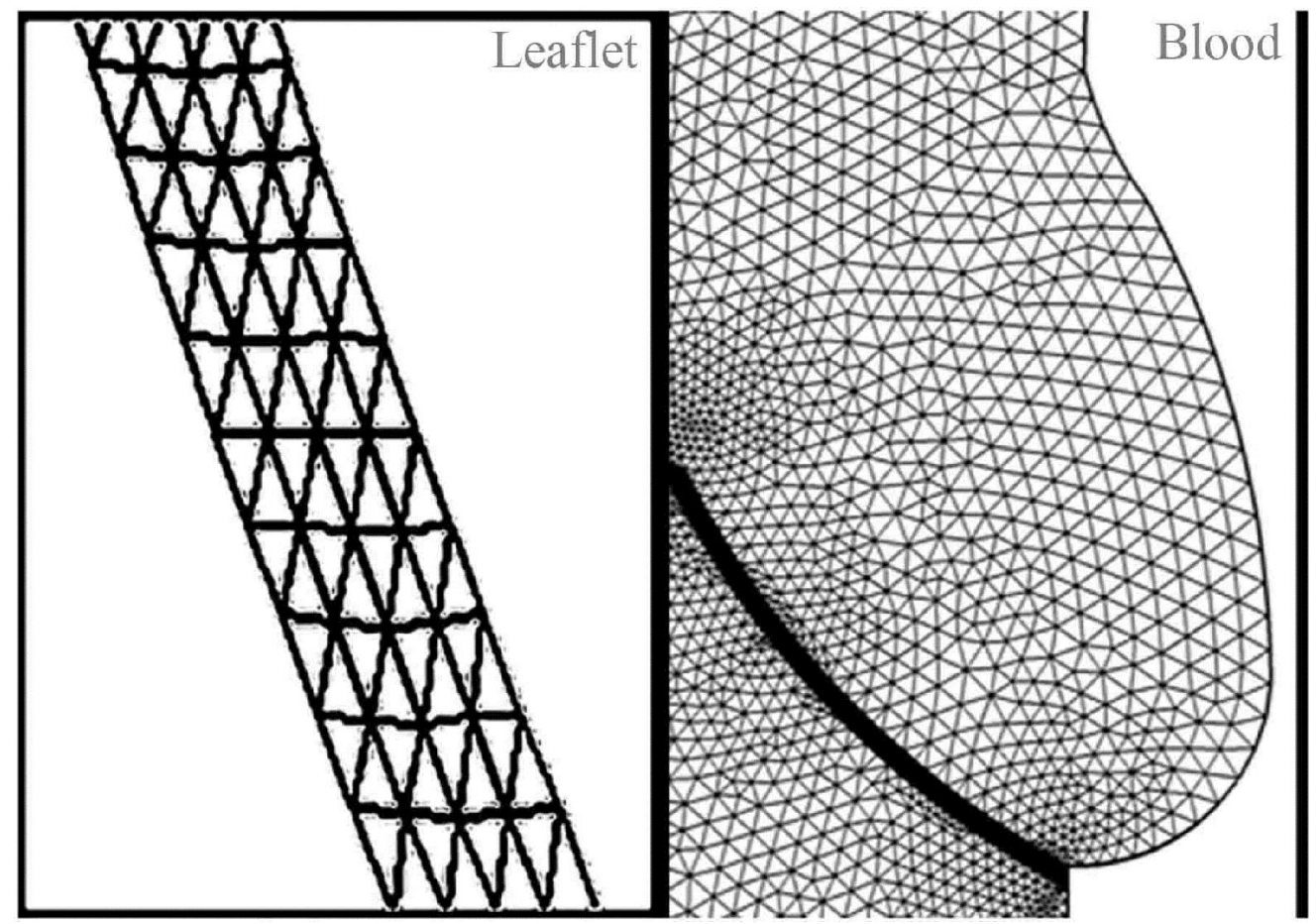

Fig. 3. Mesh model

\subsection{Analysis of fluid dynamics}

Cardiac output was calculated applying Eq. (3):

Cardiac output $=$ Stroke volume $\times$ Heart rate,

where the stroke volume was computed from ECG using Eq. (4):

Stroke volume $=$ Velocity integration $\times$ Aortic area,

where the velocity integration was automatically acquired by tracing the Doppler flow from ultrasound imaging. The aortic area was calculated utilizing Eq. (5):

$$
\text { Area }=\pi\left(\frac{D}{2}\right)^{2} \text {, }
$$

where $D$ is the calculated ascending aortic diameter after the sinotubular junction (Table 2). For FSI simulations, the mean velocity numerically was obtained at each time step of the ejection period. Eq. (6), however, was used to determine the velocity integration (used to determine both stroke volume and cardiac output).

Velocity intergration $=\oint_{0}^{\text {Ejection time }} V \cdot d t$ 
where $V$ is the fluid-velocity through the outlet boundary. Comparison of measurements of velocity integration, cardiac output and stroke volume enabled quantitative validation of the FSI model.

\section{The results}

Table 4 gives information about numerical and clinical approaches in terms of velocity integration, stroke volume as well as cardiac output for seven subjects. As far as can be seen, velocity integration figures were ranged between $0.140(\mathrm{~m})$ and $0.210(\mathrm{~m})$ for the Doppler method and $0.112(\mathrm{~m})$ to 0.198 (m) for the simulation technique. Ignoring the subject changes, the correlation factor of 0.995 was derived for the parameter of velocity integration between both approaches. As well as this, there was a difference of 5.4 to 15.3 (in percent) between two methods for the aforesaid parameter.

Furthermore, stroke volume figures were ranged between $89.75(\mathrm{ml} /$ beat) and $165.65(\mathrm{ml} / \mathrm{beat})$ for the Doppler method and 79.06 ( $\mathrm{ml} /$ beat) to 156.19 (ml/beat) for the simulation technique. Ignoring the subject changes, the correlation factor of 0.990 was derived for the parameter of stroke volume between both approaches. As well as this, there was a difference of 5.71 to 15.87 (in percent) between two methods for the aforesaid parameter.

In respect of cardiac output, figures were ranged between $89.75(\mathrm{ml} /$ beat) and $165.65(\mathrm{ml} /$ beat $)$ for the Doppler method and 79.06 ( $\mathrm{ml} /$ beat) to 156.19 (ml/beat) for the simulation technique. Ignoring the subject changes, the correlation factor of 0.990 was derived for the parameter of stroke volume between both approaches. As well as this, there was a difference of 5.71 to 15.87 (in percent) between two methods for the aforesaid parameter.

\section{Table 4}

Numerical and clinical results in terms of velocity integration, stroke volume as well as cardiac output for seven subjects

\begin{tabular}{llllllllll}
\hline & $\begin{array}{l}\text { Difference } \\
\text { of VTIN to } \\
\text { VTID }(\%)\end{array}$ & $\begin{array}{l}\text { Difference } \\
\text { of SVN to } \\
\text { SVD }(\%)\end{array}$ & $\begin{array}{l}\text { Difference } \\
\text { of CON to } \\
\text { COD }(\%)\end{array}$ & $\begin{array}{l}\text { VTID } \\
(\mathrm{m})\end{array}$ & $\begin{array}{l}\text { VTIN } \\
(\mathrm{m})\end{array}$ & $\begin{array}{l}\text { SVD } \\
(\mathrm{ml} / \mathrm{beat})\end{array}$ & $\begin{array}{l}\text { SVN } \\
(\mathrm{ml} / \mathrm{beat})\end{array}$ & $\begin{array}{l}\text { COD } \\
(\mathrm{ml} / \mathrm{min})\end{array}$ & $\begin{array}{l}\text { CON } \\
(\mathrm{ml} / \mathrm{min})\end{array}$ \\
\hline 1 & 8.9 & 9.67 & 9.67 & 0.124 & 0.112 & 97.19 & 87.79 & 7775.9 & 7023.4 \\
\hline 2 & 11.7 & 11.99 & 11.99 & 0.150 & 0.132 & 147.55 & 129.85 & 10919.4 & 9609.9 \\
3 & 12.5 & 12.86 & 12.85 & 0.140 & 0.122 & 141.64 & 123.42 & 9914.8 & 8640.1 \\
4 & 5.4 & 5.71 & 5.71 & 0.210 & 0.198 & 165.65 & 156.19 & 12755.5 & 12026.6 \\
\hline 5 & 15.3 & 15.87 & 15.86 & 0.145 & 0.122 & 111.53 & 93.82 & 5798.6 & 4878.8 \\
\hline 6 & 5.9 & 6.18 & 6.19 & 0.210 & 0.197 & 165.65 & 155.40 & 9773.7 & 9168.6 \\
\hline 7 & 11.1 & 11.91 & 11.42 & 0.140 & 0.124 & 89.75 & 79.06 & 6605.7 & 5850.7 \\
\hline
\end{tabular}

VTID: Velocity time integration by Doppler;

VTIN: Velocity time integration by numerical simulation;

SVD: Stroke volume by Doppler;

SVN: Stroke volume by numerical simulation;

COD: Cardiac output by Doppler;

CON: Cardiac output by numerical simulation;

\section{Discussion}

\section{1. study findings}

The study has applied Doppler haemodynamic measurements with an FSI technique to calculate the velocity integration, stroke volume and cardiac output non-invasively from seven healthy subjects under rest condition. Echo-Doppler gained data has been compared to FSI results. Based on authors knowledge this is the first time that the FSI discipline has been used to rest measurements of cardiovascular performance for more than one subject. In spite of the use of a simplified FSI model, estimated values generally had a difference of 5.4 to $15.87 \%$ of the values of Doppler-derived. The 
FSI model reliably predicted the velocity integration, stroke volume and cardiac output over a range of heart rates while rest. Predictions of around 85 to $95 \%$ of clinical measurement could present limitations in clinical application; therefore, linear correlations have been applied. This makes possible predictions achieved from the FSI model to be gained which are highly accurate (e.g. correlation factor $r=0.995,0.990$ and 0.990 for velocity integration, stroke volume and cardiac output, respectively). This study presents the possibility of obtaining a wide range of time-dependent as well as variable boundary conditions. This also generates a simplified two-dimensional model which could predict cardiovascular function within comparatively short solution time ( $<15$ minutes).

\subsection{Clinical application and reliability}

Catheterization has been known as the golden standard to measure velocity integration, stroke volume and cardiac output (Lavdaniti, 2008). Although, it is an invasive technique with possible risks like cardiac arrhythmia, heart failure and even death (Lavdaniti, 2008). As well as this, Thermodilution exposes the subject and doctor to harmful radiation, thus, it is not usual practice. Whereas in contrast, the use of a numerical technique allows the estimation of cardiac performance by non-invasive calculations. Mathematical simulation, moreover, allows easier estimation of cardiac output than using echo-Doppler. Also, it does not include any inter- and intra-observer validity variables which are the stages for performing ECG.

\subsection{Comparison to literature}

Following a literature search it has not been found a prior comparable research that applies a clinical and numerical methods for several subjects to predict cardiac performance during rest. In this study, subject specific velocity integration, stroke volume and cardiac output were predicted at a range of heartbeats. Nevertheless, this study compares in a good manner to other numerical approaches used to evaluate cardiac function at rest. This model estimated a cardiac output at rest of $8171.15 \mathrm{ml} / \mathrm{min}$, averagely for all subjects, can be compared to predictions $7500 \mathrm{ml} / \mathrm{min}$ (Korakianitis \& Shi, 2006; Kim et al., 2009). Such assessments have applied a finite element technique coupled a lumped parameter method, a Wind-Kassel approach (Korakianitis \& Shi, 2006), as well as an electrical integration circuit (Podnar et al., 2002). Data derived from Christie et al. (1987) agrees with our results. Moreover, it could be noted that a non-athlete, could be anticipated to have a peak stroke volume of $110 \mathrm{ml}$ with a heart rate of $195 \mathrm{bpm}$ (Guyton \& Hall, 1996; Porth, 2007). Because our subject is a non-athlete, our modelling results are nearly well with the literature.

\section{4 Limitations}

The main limitations are:

- Simplifications of the mechanical leaflet properties, in the model: The model was considered isotropic, linear and homogenous. This probably has resulted in differences between our clinical and numerical results.

- Aortic wall was considered rigid; although this resulted in a faster simulation and this is clinically important.

- Numerical estimation of hemodynamic is obtained based on generalised information; the mechanical properties of the aortic valve of the volunteer are unknown. Although we have applied agreed values in the literature.

- A two-dimensional model was used to assess a three-dimensional biological system. The estimations might ameliorated by utilization of a three-dimensional model. However, a 2D simulation has the merit of a shorter solution time. 
- Blood was considered to be Newtonian fluid and incompressible. This can affect hemodynamic estimations, but we have concentrated on hemodynamic trends.

Despite model limitations, we demonstrate good agreement with clinical measurements and the general literature (Bahraseman et al, 2013). Currently, there is a trend towards patient specific models (e.g. Öhman et al, 2011) due to potential benefits in aiding treatment/diagnosis for an individual. A three-dimensional model may provide more exact predictions; although it would also increase the processing time which is currently less than 15 minutes. This would hold demerits for clinical applications.

\section{Conclusion}

The subject specifics two-dimensional models of the aortic valve have been applied to make hemodynamic estimations at rest. Despite the use of a simplified FSI model, estimated values generally are in good agreement with the values of Doppler-derived.

\section{References}

AL-Atabi, M., Espino, D. M., \& Hukins, D. W. (2010). Computer and experimental modelling of blood flow through the mitral valve of the heart. Journal of Biomechanical Science and Engineering, 5(1), 78-84.

Bahraseman, H. G., Hassani, K., Navidbakhsh, M., Espino, D. M., Sani, Z. A., \& Fatouraee, N. (2013). Effect of exercise on blood flow through the aortic valve: a combined clinical and numerical study. Computer methods in biomechanics and biomedical engineering, (ahead-ofprint), 1-14.

Bellhouse, BJ. (1972). The fluid mechanics of heart valves In: Cardiovascular Fluid Dynamics. Volume 1. Bergel DH (ed). London, Academic Press.

Bodnar, E., Grunkemeier, G. L., \& Gabbay, S. (1999). Heart valve replacement: A statistical review of 35 years' results-Discussion.

Butchart, E. G., Ionescu, A., Payne, N., Giddings, J., Grunkemeier, G. L., \& Fraser, A. G. (2003). A new scoring system to determine thromboembolic risk after heart valve replacement. Circulation, 108(10 suppl 1), II-68.

Christie, J., Sheldahl, L. M., Tristani, F. E., Sagar, K. B., Ptacin, M. J., \& Wann, S. (1987). Determination of stroke volume and cardiac output during exercise: comparison of twodimensional and Doppler echocardiography, Fick oximetry, and thermodilution. Circulation, 76(3), 539-547.

Comsol Users Manual. (2011). Comsol Multiphysics Users Guide. Londen, Comsol Ltd.

Criner, G. J., Barnette, R. E., \& D'Alonzo, G. E. (Eds.). (2010). Critical care study guide: text and review. Springer.

De Hart, J., Peters, G. W., Schreurs, P. J., \& Baaijens, F. P. (2000). A two-dimensional fluidstructure interaction model of the aortic value. Journal of biomechanics, 33(9), 1079-1088.

De Hart, J., Peters, G. W. M., Schreurs, P. J. G., \& Baaijens, F. P. T. (2003a). A three-dimensional computational analysis of fluid-structure interaction in the aortic valve. Journal of biomechanics, 36(1), 103-112.

De Hart, J., Baaijens, F. P. T., Peters, G. W. M., \& Schreurs, P. J. G. (2003b). A computational fluidstructure interaction analysis of a fiber-reinforced stentless aortic valve. Journal of biomechanics, 36(5), 699-712.

Donea, J., Giuliani, S., \& Halleux, J. P. (1982). An arbitrary Lagrangian-Eulerian finite element method for transient dynamic fluid-structure interactions. Computer Methods in Applied Mechanics and Engineering, 33(1), 689-723.

Dowell, E. H., \& Hall, K. C. (2001). Modeling of fluid-structure interaction. Annual Review of Fluid Mechanics, 33(1), 445-490. 
Espino, D. M., Shepherd, D. E., \& Hukins, D. W. (2012). Evaluation of a transient, simultaneous, arbitrary Lagrange-Euler based multi-physics method for simulating the mitral heart valve. Computer Methods in Biomechanics and Biomedical Engineering, (ahead-of-print), 1-9.

Espino, D. M., Shepherd, D. E., \& Hukins, D. W. (2013). Development of a transient large strain contact method for biological heart valve simulations. Computer Methods in Biomechanics and Biomedical Engineering, 16(4), 413-424.

Espino, D. M., Shepherd, D. E. T., \& Hukins, D. W. L. (2013). A Simple Method for Contact modelling in an Arbitrary frame of Reference within multi-Physics Software. Journal of Mechanics, 29(03), N9-N14.

Formaggia, L., \& Nobile, F. (1999). A stability analysis for the arbitrary Lagrangian Eulerian formulation with finite elements. East West Journal of Numerical Mathematics, 7, 105-132.

Govindarajan, V., Udaykumar, H. S., Herbertson, L. H., Deutsch, S., Manning, K. B., \& Chandran, K. B. (2010). Two-dimensional FSI simulation of closing dynamics of a tilting disc mechanical heart valve. Journal of medical devices, 4(1), 11001.

Giddens, D. P., Yoganathan, A. P., \& Schoen, F. J. (1993). Prosthetic cardiac valves. Cardiovascular Pathology, 2(3), 167-177.

Griffith, B. E., \& Peskin, C. S. (2005). On the order of accuracy of the immersed boundary method: higher order convergence rates for sufficiently smooth problems. Journal of Computational Physics, 208(1), 75-105.

Griffith, B. E., Hornung, R. D., McQueen, D. M., \& Peskin, C. S. (2007). An adaptive, formally second order accurate version of the immersed boundary method. Journal of Computational Physics, 223(1), 10-49.

Griffith, B. E., Luo, X., McQueen, D. M., \& Peskin, C. S. (2009). Simulating the fluid dynamics of natural and prosthetic heart valves using the immersed boundary method. International Journal of Applied Mechanics, 1(01), 137-177.

Guyton, A. C., Hall, J. E. (1996). Overview of circulation; medical physics of pressure. Textbook of Medical Physiology. 9th ed. Pennsylvania: WB Saunders.

Kim, H. J., Vignon-Clementel, I. E., Figueroa, C. A., LaDisa, J. F., Jansen, K. E., Feinstein, J. A., \& Taylor, C. A. (2009). On coupling a lumped parameter heart model and a three-dimensional finite element aorta model. Annals of biomedical engineering, 37(11), 2153-2169.

Koch, T. M., Reddy, B. D., Zilla, P., \& Franz, T. (2010). Aortic valve leaflet mechanical properties facilitate diastolic valve function. Computer methods in biomechanics and biomedical engineering, 13(2), 225-234.

Korakianitis, T., \& Shi, Y. (2006). Numerical simulation of cardiovascular dynamics with healthy and diseased heart valves. Journal of biomechanics, 39(11), 1964-1982.

Labrosse, M. R., Lobo, K., \& Beller, C. J. (2010). Structural analysis of the natural aortic valve in dynamics: from unpressurized to physiologically loaded. Journal of biomechanics, 43(10), 19161922.

Laske, A., Jenni, R., Maloigne, M., Vassalli, G., Bertel, O., \& Turina, M. I. (1996). Pressure gradients across bileaflet aortic valves by direct measurement and echocardiography. The Annals of thoracic surgery, 61(1), 48-57.

Murphy, S. L., Xu, J., \& Kochanek, K. D. (2012). National Vital Statistics Reports. National Vital Statistics Reports, 60(4), 1.

Nobili, M., Sheriff, J., Morbiducci, U., Redaelli, A., \& Bluestein, D. (2008). Platelet activation due to hemodynamic shear stresses: damage accumulation model and comparison to in vitro measurements. ASAIO journal (American Society for Artificial Internal Organs: 1992), 54(1), 64.

Öhman, C., Espino, D. M., Heinmann, T., Baleani, M., Delingette, H., \& Viceconti, M. (2011). Subject-specific knee joint model: Design of an experiment to validate a multi-body finite element model. The Visual Computer, 27(2), 153-159. 
Park, S. H., Lee, S. J., Kim, J. Y., Kim, M. J., Lee, J. Y., Cho, A. R., ... \& Jin, D. K. (2011). Direct comparison between brachial pressure obtained by oscillometric method and central pressure using invasive method. Soonchunhyang Medical Science, 17(2), 65-71.

Pedley, T. J., Schroter, R. C., Seed, W. A., \& Parker, K. H. (1978). The mechanics of the circulation (Vol. 192633236). Oxford: Oxford University Press.

Piérard, L. A., \& Lancellotti, P. (2007). Stress testing in valve disease. Heart, 93(6), 766-772.

Podnar, T., Runovc, F., \& Kordaš, M. (2002). Simulation of cardiovascular physiology: the diastolic function (s) of the heart. Computers in biology and medicine, 32(5), 363-377.

Porth, C. (2007). Essentials of pathophysiology: Concepts of altered health states. Lippincott Williams \& Wilkins.

Van de Vosse, F. N., De Hart, J., Van Oijen, C. H. G. A., Bessems, D., Gunther, T. W. M., Segal, A., ... \& Baaijens, F. P. T. (2003). Finite-element-based computational methods for cardiovascular fluid-structure interaction. Journal of engineering mathematics, 47(3-4), 335-368.

Weinberg, E. J., \& Kaazempur Mofrad, M. R. (2008). A multiscale computational comparison of the bicuspid and tricuspid aortic valves in relation to calcific aortic stenosis. Journal of biomechanics, 41(16), 3482-3487.

Winslow, A. M. (1966). Numerical solution of the quasilinear Poisson equation in a nonuniform triangle mesh. Journal of computational physics, 1(2), 149-172. 